\title{
Fatal neurotoxic envenomation following the bite of a greater black krait (Bungarus niger) in Nepal: a case report
}

\author{
Deb Prasad Pandey ${ }^{1 *}$, Sanjib Kumar Sharma², Emilie Alirol ${ }^{3,4}$, François Chappuis ${ }^{3}$ and Ulrich Kuch $^{5}$
}

\begin{abstract}
Background: Neurotoxic envenomation following bites by kraits (Bungarus species) is a leading cause of snakebite mortality in South Asia. Over a long time, this had been attributed only to one species, the common krait (Bungarus caeruleus). However, recent research has provided increasing evidence of the involvement of several krait species. Here, we report a fatal case of neurotoxic envenomation following the bite of a greater black krait (Bungarus niger) in Nepal.

Case presentation: A 33-year-old man was bitten in the outdoor corridor of his home in the eastern hills of llam district while handling a snake he thought to be non-venomous. He subsequently developed severe abdominal pain, frequent vomiting, and signs of neurotoxic envenomation leading to respiratory paralysis. The patient did not respond to Indian polyvalent antivenom given $4 \mathrm{~h}$ after the bite and died under treatment $8 \mathrm{~h}$ after the bite. This is the second time that a B. niger was observed in Nepal, the first documented case of envenomation by this species in the country and the sixth reported case worldwide.

Conclusions: Previous distribution records - from eastern India and western Nepal, from western hills in Nepal, and from lowland localities in India and Bangladesh - indicate risk of envenomation by B. niger throughout the low and intermediate elevations of Nepal up to at least 1,500 m above sea level. As very few people in Nepal bring killed snakes to healthcare centers and because there is a general belief among local people that there are no kraits in the hills, bites by B. niger are likely to be misdiagnosed and underreported.
\end{abstract}

Keywords: Bungarus niger, Neurotoxicity, Krait, Envenomation, Antivenom, Snakebite

\section{Background}

For a very long time, krait bite envenomation in South Asia was thought to be due to a single species, the widely distributed common krait (Bungarus caeruleus), whose venom has consequently been used in the production of polyvalent antivenoms in India [1]. However, several other species of krait occur in South Asia, and some of these were recently shown to contribute to regional snakebite morbidity and mortality [2-7].

The greater black krait (Bungarus niger Wall, 1908) is widely distributed in South and Southeast Asia where it has been recorded in India, Bangladesh, Bhutan, Myanmar, and Nepal [2, 4, 8-10]. Bungarus

\footnotetext{
* Correspondence: debpandey@gmail.com

${ }^{1}$ Kaligandaki Health Foundation, Kawasoti, Nawalparasi, Nepal

Full list of author information is available at the end of the article
}

niger is superficially similar in appearance to the lesser black krait (Bungarus lividus) (Fig. 1) which has caused fatalities in India and Nepal [5]. However, $B$. niger is distinguishable from $B$. lividus based on the size and shape of the middorsal row of scales (Fig. 1). Although $B$. niger has been recognized as a distinct species for more than a century, only a single series of five confirmed cases of envenomation by this species in Bangladesh has been published [4, 11]. Strikingly, $B$. niger was found to cause both neurotoxic and myotoxic envenomation in victims as well as in animal models, a new syndrome of snakebite envenomation in South Asia that entails additional clinical challenges [5]. Available antivenoms in this region, produced by various Indian manufacturers, are raised against only four species of venomous snakes, namely, common krait (B. caeruleus), spectacled cobra (Naja naja), Russell's viper (Daboia russelii), 


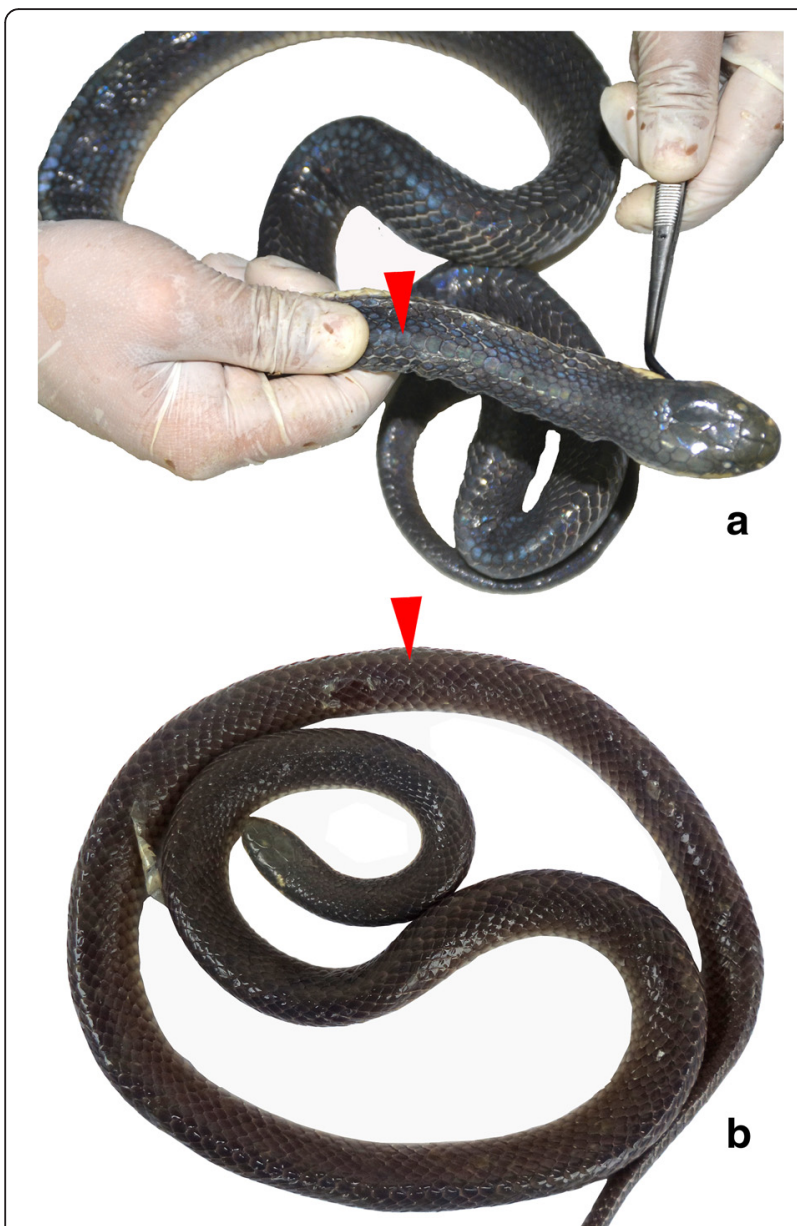

Fig. 1 Dorsal view of a Bungarus niger and $\mathbf{b}$ Bungarus lividus. The entirely black dorsum of both species distinguishes them from other South Asian kraits. In (a) B. niger the middorsal scales along the vertebral column (red arrows) are greatly enlarged and hexagonal in shape, whereas in (b) B. lividus the middorsal scales are similar in size and shape to those of adjacent scale rows (photo by Deb Prasad Pandey)

and saw-scaled viper (Echis carinatus) [1]. Whether or not these or other antivenoms can neutralize the lethal effects of $B$. niger venom is still unknown. In the present study, we present the first case of B. niger envenomation in Nepal.

\section{Case presentation}

A 33-year-old male laborer found a snake on the outdoor corridor of his house at Golbasti, Ilam municipality, Ilam district, in the eastern hills of Nepal (N $26.89874^{\circ}, \mathrm{E} 87.91900^{\circ}$, elevation $1515 \mathrm{~m}$ a.s.l.) at $6: 30$ p.m. on 4 August 2012. Believing that it was a nonvenomous snake, he picked it up and carelessly handled the snake. The victim, who had been under the influence of locally produced alcoholic drink ("Jaand"), hit the back of the snake once with a wooden plank and then picked the snake up again and played with it joining its head with the tail. When his wife urged him not to handle the snake, he replied that the snakes in the hills of Nepal were non-venomous. Unresponsive to advice, the man touched and pressed the injured back of the snake. In this moment, at 7:00 p.m., the snake bit the index finger of his right hand. The man then picked the snake up and put it in a bucket.

After the bite, the patient's brother applied a tourniquet to his forearm. The patient then walked for about $10 \mathrm{~min}$ to his neighbor's house. The neighbor immediately carried him on a motorcycle to the hospital in Ilam Bazaar (Ilam district, Nepal, distance $2.2 \mathrm{~km}$ ) where he arrived at 7:30 p.m. On admission, there were fang marks indicating multiple bites with slight bleeding from the bite sites. Healthcare staff washed the finger, applied a crepe bandage, and infused saline over $30 \mathrm{~min}$. At 8:00 p.m., the patient was suffering from burning sensation at the bite site and appeared significantly ill, he had developed bilateral ptosis, difficulty in speaking, slurred speech, and had pain in the chest and abdomen. Moreover, he vomited for the first time. As antivenom was not available in this hospital, arrangements were made to transfer the patient to the snakebite treatment center of Charali in Jhapa district. At 8:30 p.m., the ambulance went from Ilam to Charali with the patient. At 9:00 p.m., difficulty in speaking increased so the patient started to communicate by nodding his head, shaking his hands and writing something with his index finger which his illiterate wife could not understand. He also vomited for a second time and, at 9:15 p.m. and 10:30 p.m., a third and fourth time. At 10:50 p.m., when the ambulance reached Charali, the patient was semi-conscious.

On admission to the Charali Snakebite Treatment Center (about $4 \mathrm{~h}$ after the bite), the attending healthcare staff were not able to find any fang marks, presumably as an effect of the bite site having been washed at Ilam Hospital. There was no detectable swelling or inflammation. However, bilateral ptosis, difficulty in swallowing, slurred speech, and difficulty in speaking were recorded at 11:00 p.m. Antivenom was administered at 11:15 p.m. in an initial bolus dose of $100 \mathrm{~mL}$ of polyvalent anti-snake venom serum (produced by VINS Bioproducts Ltd., targeted against $B$. caeruleus, $N$. naja, E. carinatus, and $D$. russelii snake venoms) preceded by a subcutaneous injection of adrenaline $(0.25 \mathrm{~mL}$ of $1: 1000$ solution) [12]. Atropine $(0.6 \mathrm{mg})$ and neostigmine $(0.5 \mathrm{mg})$ were given with the same infusion as an attempt of anticholinesterase treatment. At 11:20 p.m., the patient vomited for the fifth time and received antiemetic treatment in the form of an intravenous injection of metoclopramide $(10 \mathrm{mg})$. At 11:35 p.m., the patient showed rashes near the infusion cannula at the left hand and was given an intravenous injection of pheniramine maleate $(10 \mathrm{mg})$. The same dosage of atropine and neostigmine treatment was repeated 
at 11:45 p.m., although the first injections had not resulted in any improvement.

At 00:05 a.m. on 5 August 2012, the following symptoms were noted: the patient was unable to speak, could not protrude the tongue, swallow, or frown. A second dose of $100 \mathrm{~mL}$ of antivenom was injected and his airways cleared using a suction pump. At 00:15 a.m. he was again given atropine and neostigmine $(0.6$ and 0.5 $\mathrm{mg}$, respectively). At 00:25 a.m., the patient was reevaluated and found to show no improvement. At 00:30 a.m., he received a third dose of $100 \mathrm{~mL}$ of antivenom by slow intravenous bolus injection. By this time, the patient's respiratory rate was altered, his blood pressure lowered, and blood oxygen level decreased. Attempts were made to intubate the patient but failed three times. Then, attempts were made to manually ventilate him with a mask and Ambu bag. When his pulse rate decreased to 55 , he was given atropine (0.6 $\mathrm{mg}$, subcutaneously) which increased the rate. At 00:45 a.m., endotracheal intubation was successful, but the patient's blood oxygen level was down to $40 \%$ and his blood pressure dropped, immediately followed by cardiac arrest. Cardiopulmonary resuscitation was attempted until he was declared dead at 01:00 a.m. ( $8 \mathrm{~h}$ after the bite). Because of the absence of laboratory facilities in the Charali Snakebite Treatment Center, no information on the patient's ECG, potassium and sodium levels, total leucocyte count, blood urea, creatine kinase, albumin, myoglobin or blood cells in urine was available.

The snake specimen brought to the Charali Snakebite Treatment Center by the snakebite victim was a male $B$. niger measuring $1,357 \mathrm{~mm}$ in total length. The snake was labelled and preserved in $70 \%$ ethanol. After morphological examination and taxonomic identification by one of the authors (DPP), it was permanently deposited in the snake collection of the B. P. Koirala Institute of Health Sciences, Dharan, Nepal (voucher number 02-023).

\section{Discussion}

This is the first report of $B$. niger bite envenomation in Nepal, and only the second record of this species from this country. This case report highlights the diversity of snake species causing fatalities in Nepal, and emphasizes the need of preserving snakes brought by snakebite victims to better understand snakebite epidemiology. In addition, it corroborates recent publications describing previously overlooked snake species that contribute to snakebite mortality in South Asia [1, 4, 13].

Including the present one, six proven cases of $B$. niger envenomation with three fatalities have been reported since these snakes had first been recognized as a distinct species, in the year 1908 [11]. Five of the bites occurred in Bangladesh [4]. The known altitudinal distribution of this species ranges from near sea level in Bangladesh up to at least $1,500 \mathrm{~m}$ in Nepal $[4,8,14]$. As there are records of this species from India, western and eastern Nepal, and two records in the mid-western and eastern hills of Nepal (the present one), B. niger may be expected to occur throughout the latter country $[8,10,15,16]$. Moreover, it may be potentially found at lower and higher altitudes than those of the two presently known collecting sites $(1,450$ and 1,515 m). In Bangladesh, B. niger inflicted bites $(n=3)$ while being handled (like the present case), on sleeping people $(n=2)$, and on a person who was cutting wood [4]. Similar to B. caeruleus bites, B. niger bites occurred in and around houses in the evening (present case), at night ( $n=1,2: 00$ a.m.), and in the morning (4:00 to 9:00 a.m.) [4, 17-19]. Therefore, people should be careful while performing household and field activities especially at twilight and night during the rainy season (July-August) [10].

Most of the community people we have talked to in the highlands of Nepal believe that the deadly venomous nocturnal kraits are absent in the hills. The victim, his family members, and other locals did not know that this snake was venomous. Tillack and Grossmann [10] reported a similar ignorance of this species among inhabitants of the western hills of Nepal when they first recorded $B$. niger there. In the present case, the snake apparently was quite docile initially and did not attempt to bite until it was seriously injured. This kind of inoffensive behavior, typical of most kraits at least during daytime, may be misleading villagers who think that these snakes are not dangerous.

Although the B. niger bite occurred in a place connected by a gravel $(0.5 \mathrm{~km})$ and paved road $(74 \mathrm{~km})$ with the nearest Snakebite Treatment Center in Charali, Jhapa district, accessible by a four-wheel vehicle within 10 to 30 $\mathrm{min}$, the patient lost precious time (about $1 \mathrm{~h}$ ) getting to the local health facility where no antivenom was available. This highlights a need for informing people about the nearest healthcare facility that delivers adequate treatment for snakebite envenomation and has antivenom (a WHO recognized 'essential drug') on stock.

In contrast to the $B$. niger bite cases in Bangladesh, we could not evaluate the possibility of myotoxic envenomation and ensuing complications in this patient (i.e., rhabdomyolysis, myoglobinuria, hyperkalemia, acute renal failure, etc.) because of the absence of laboratory facilities [4]. We noted symptoms of burning sensation at the bite site, bilateral ptosis, abdominal pain, and frequent vomiting similar to B. caeruleus and B. lividus envenomation $[5,17,18]$.

In the Bangladesh series of $B$. niger envenomation, three of the five patients recovered completely after about 3 to 10 days (two of these requiring mechanical ventilation and treatment with antivenom), and two died within $47 \mathrm{~h}$ after the bite due to respiratory paralysis and acute renal failure [4]. Collectively, these observations indicate delayed or no 
recovery after envenomation, despite the administration of Indian polyvalent antivenoms. The efficacy of the currently available antivenoms in the treatment of $B$. niger envenomation is therefore doubtful.

\section{Conclusions}

Although only six proven cases of envenomation by $B$. niger have been published from Bangladesh and Nepal, more fatalities due to the bite of this species can be expected to occur in a large region of South Asia. Epidemiological studies aimed at identifying the snake species responsible for bites should therefore be conducted. Community-based health education, highlighting simple messages on snakebite prevention and rapid transport of victims to appropriate medical care, should be reinforced. Health care workers in snakebite treatment centers and ambulances in South Asia and beyond should be trained to perform intubation and assisted ventilation as a priority, as currently available antivenoms are unlikely to be effective against envenomation by B. niger (and probably other Bungarus species). Furthermore, methods of preventing and treating acute renal failure -as an additional possible clinical challenge after bites by this and other snake species- should be included in training programs [20].

\section{Acknowledgements}

We are grateful to the deceased patient's spouse for sharing with us details of the B. niger bite case, its pre-hospital care, and the evolution of symptoms until the patient's arrival at the Charali Snakebite Treatment Center. We are also grateful to Huta Raj Katwal, Shyam Krishna Rajbhandari, and Dr. Lok Raj Chaurasia of Charali Snakebite Treatment Center for providing the clinical details of the case, and to Mamit Rai for administrative support. We thank anonymous reviewers for their constructive comments on this article.

\section{Funding}

This study was funded by the Swiss National Science Foundation (Project number IZ70ZO-131223). The foundation did not have any role in the design, collection, analysis, and interpretation of data, nor in the writing or the decision of submitting the manuscript for publication.

\section{Authors' contributions}

DPP identified the snake, conducted interviews and collected primary data. DPP and UK drafted the manuscript. EA, FC, SKS, and UK conceived the study during which the case was recorded. SKS observed the reported case. $E A, F C$, and SKS contributed to manuscript writing. All authors read and approved the final manuscript.

\section{Competing interests}

The authors declare that there are no competing interests.

\section{Consent for publication and ethics approval}

Written informed consent was obtained from the deceased patient's wife for the publication of this case report. The study was approved by the the Ethics Committee of Geneva University Hospitals, Ethical Review Board of the B.P. Koirala Institute of Health Sciences, and by the Nepal Health Research Council.

\section{Author details}

${ }^{1}$ Kaligandaki Health Foundation, Kawasoti, Nawalparasi, Nepal. ${ }^{2}$ Department of Internal Medicine, B.P. Koirala Institute of Health Sciences, Dharan, Nepal. ${ }^{3}$ Clinical Trial Unit, Clinical Research Centre and Division of Tropical and Humanitarian Medicine, University Hospitals of Geneva, Geneva, Switzerland. ${ }^{4}$ Médecins Sans Frontières UK, London, UK. Institute of Occupational Medicine, Social Medicine and Environmental Medicine, Goethe University, Frankfurt am Main, Germany.
Received: 19 December 2015 Accepted: 24 May 2016

Published online: 03 June 2016

\section{References}

1. Alirol E, Sharma SK, Bawaskar HS, Kuch U, Chappuis F. Snake bite in South Asia: a review. PLoS Negl Trop Dis. 2010;4(1):e603.

2. Whitaker R, Captain A. Snakes Of India: The Field Guide. 1st ed. Chengalpattu, Chennai: Draco Books; 2004.

3. Sharma SK, Pandey DP, Shah KB, Tillack F, Chappuis F, Thapa CL, et al. Venomous Snakes Of Nepal: A Photographic Guide. 1st ed. Dharan: Lalitpur: B. P. Koirala Institute of Health Sciences; 2013.

4. Faiz MA, Ghose A, Ahsan MF, Rahman MR, Amin MR, Hassan MMU, et al. The Greater Black Krait (Bungarus niger), a newly recognized cause of neuro-myotoxic snake bite envenoming in Bangladesh. Brain. 2010:133(11):3181-93.

5. Kuch U, Sharma SK, Alirol E, Chappuis F. Fatal neurotoxic envenomation from the bite of a Lesser Black Krait (Bungarus lividus) in Nepal. Southeast Asian J Trop Med Public Health. 2011;42(4):960-4.

6. Pillai LV, Ambike D, Husainy S, Khaire A, Captain A, Kuch U. Severe neurotoxic envenoming and cardiac complications after the bite of a 'Sind Krait' (Bungarus cf. sindanus) in Maharashtra, India. Trop Med Health. 2012:40(3):103-8.

7. Pandey DP. Venomous snakes of medical relevance in Nepal: study on species, epidemiology of snake bite and assessment of risk factors of envenoming and death. Frankfurt: Goethe University; 2015. http:// publikationen.ub.uni-frankfurt.de/frontdoor/index/index/docld/38272. Accessed 15 Oct 2015

8. Bauer AM, Gunther R. A preliminary report on the reptile fauna of the Kingdom of Bhutan with the description of a new species of scincid lizard (Reptilia: Scincidae). Asiat Herpetol Res. 1992;4:23-36.

9. Leviton AE, Zug GR, Vindum JV, Wogan GOU. Handbook to the dangerously venomous snakes of Myanmar. 1st ed. San Francisco: California Academy of Sciences; 2008.

10. Tillack F, Grossmann W. A new record for the snake fauna of Nepal: Bungarus niger Wall, 1908 (Reptilia: Serpentes: Elapidae). Sauria. 2001;23(1):3-9.

11. Wall F. A popular treatise of the common Indian snakes. Part VIII. J Bombay Nat Hist Soc. 1908:18:711-35.

12. de Silva HA, Pathmeswaran $A$, Ranasinha $C D$, Jayamanne $S$, Samarakoon $S B$, Hittharage $A$, et al. Low-dose adrenaline, promethazine, and hydrocortisone in the prevention of acute adverse reactions to antivenom following snakebite: a randomised, double-blind, placebo-controlled trial. PLoS Med. 2011;8(5), e1000435

13. World Health Organization. Guidelines for the management of snakebites. 2nd ed. New Delhi: World Health Organization; 2010.

14. Grosselet O, Vauché M, Gupta A, Gupta S. Bungarus niger Wall, 1908 (Reptilia: Serpentes: Elapidae): extension of range to Cachar District, Assam, India. Russ J Herpetol. 2004;11(1):10-1.

15. Theophilus E, Captain A, Tillack F, Kuch U. Reptilia, Elapidae, Bungarus niger: distribution extension and first record for the state of Uttarakhand, India, with notes on snakebites in the Gori River valley. Check List. 2008;4(4):404-9.

16. Wall F. Notes on snakes collected in upper Assam. Part II. J Bombay Nat Hist Soc. 1910;19:825-45.

17. Ariaratnam CA, Sheriff MHR, Theakston RDG, Warrell DA. Distinctive epidemiologic and clinical features of Common Krait (Bungarus caeruleus) bites in Sri Lanka. Am J Trop Med Hyg. 2008;79(3):458-62.

18. Kularatne SAM. Common Krait (Bungarus caeruleus) bite in Anuradhapura, Sri Lanka: a prospective clinical study, 1996-98. Postgrad Med J. 2002;78(919):276-80.

19. Bawaskar HS, Bawaskar PH. Envenoming by the Common Krait (Bungarus caeruleus) and Asian Cobra (Naja naja): clinical manifestations and their management in a rural setting. Wilderness Environ Med. 2004:15(4):257-66.

20. Sharma SK. Snakebite and acute kidney injury: we must do better! Indian Pediatr. 2015:52:570-1. 